\title{
Acute Intermittent Porphyria Presenting with Posterior Reversible Encephalopathy Syndrome: A Rare Cause of Abdominal Pain and Seizures
}

\author{
Sarala Kumari Daram ${ }^{1}$, Murthy NLN Arumilli ${ }^{2}$, L Siva Kumar Reddy ${ }^{3}$, Duvvuru Nageshwar Reddy ${ }^{4}$, Revanth Motor ${ }^{5}$
}

\begin{abstract}
Acute intermittent porphyria (AIP) is an acute neurovisceral porphyria caused due to inherited deficiency of porphobilinogen deaminase (also called hydroxymethylbilane synthase) (HMBS) in the heme biosynthesis pathway. AIP is rarely associated with posterior reversible encephalopathy syndrome (PRES), which is a clinicoradiological condition caused by the failure of the posterior circulation to autoregulate, resulting in cerebral edema, headaches, nausea, and seizures. AIP should be considered when a patient presents with unexplained abdominal pain and seizures. This association is important because drugs used in the management of seizures may worsen an attack of AIP. This case report describes a young woman who presented with AIP and PRES with seizures.

Keywords: Acute intermittent porphyria, Porphyria, Posterior reversible encephalopathy syndrome.

Indian Journal of Critical Care Medicine (2020): 10.5005/jp-journals-10071-23532
\end{abstract}

\section{INTRODUCTION}

Acute intermittent porphyria (AIP) is a rare disorder affecting 1 in 75,000 people, and the diagnosis is often delayed due to diverse clinical presentations. Acute attacks are characterized by abdominal pain associated with autonomic, neurological, and psychiatric symptoms. Acute attacks are provoked by certain drugs, alcoholic beverages, endocrine factors, calorie restriction, stress, and infections and usually resolve within 2 weeks. Medication and surgery are the most common triggers. ${ }^{1}$

Posterior reversible encephalopathy syndrome (PRES) is a neurological disorder characterized by varied neurological signs and symptoms and typical neuroimaging findings. Clinical features seen in PRES are headache, seizures, visual disturbances, or mental status changes. Neuroimaging findings suggestive of PRES are characteristic parieto-occipital gyriform lesions on T2-weighted MRI.

AIP is rarely associated with PRES. Here we describe a young woman who presented with AIP and PRES with seizures.

\section{Case Description}

A 20-year-old lady presented to our hospital with complaints of intermittent abdominal pain for 20 days which was diffuse, colicky in nature, nonradiating, and associated with multiple episodes of vomiting. She also had burning and tingling sensation of the bilateral lower limbs since 3-5 days. There was no history of fever, burning micturition, or menstrual abnormalities. She was previously evaluated elsewhere for similar complaints episodically over the last 6 months, where she underwent USG Abdomen and CECT Abdomen, which were not contributory, and the diagnosis was inconclusive. She had high blood pressure recordings (BP) on admission (BP-160/100 $\mathrm{mm} \mathrm{Hg}$ ). She was initially admitted to the wards and was being evaluated for pain in the abdomen. On day 2 , she had an episode of generalized tonic-clonic seizure (GTCS)
${ }^{1-3}$ Department of Critical Care Medicine, AIG Hospitals, Hyderabad, Telangana, India

${ }^{4}$ Department of Medical Gastroenterology, AIG Hospitals, Hyderabad, Telangana, India

${ }^{5}$ Department of Radiodiagnosis, AIG Hospitals, Hyderabad, Telangana, India

Corresponding Author: Murthy NLN Arumilli, Department of Critical Care Medicine, AIG Hospitals, Hyderabad, India, Phone: +91 9611234594, e-mail: dranlnmurthy@gmail.com

How to cite this article: Sarala Kumari D, Murthy NLN Arumilli, Siva Kumar Reddy L, Nageshwar Reddy D, Motor R. Acute Intermittent Porphyria Presenting with Posterior Reversible Encephalopathy Syndrome: A Rare Cause of Abdominal Pain and Seizures. Indian J Crit Care Med 2020;24(8):724-726.

Source of support: Nil

Conflict of interest: None

in the ward followed by post-ictal state. She was transferred to the MICU for further observation and management.

Immediately on arrival to MICU, she had one more episode of GTCS which was terminated by Inj. Lorazepam, and she was administered a loading dose of inj. leviteracetam. She was initiated on IV Labetalol infusion in view of persistent hypertension (IABP recordings $>200 / 120 \mathrm{~mm} \mathrm{Hg}$ ). She underwent MRI Brain which was suggestive of PRES and also revealed sub-ependymal heterotopia (Figs $1 \mathrm{~A}$ and $\mathrm{B}$ ). Interictal electroencephalogram was suggestive of moderate encephalopathy. In view of the persistently high BP recordings and seizures in the background of unexplained pain abdomen, possibility of porphyria was considered, and spot urine porphobilinogen was sent. Qualitative spot urine porphobilinogen test was positive. She was initiated on $25 \%$ dextrose infusion and high carbohydrate (glucose) diet. She also had intermittent episodes of irritability and agitation possibly suggestive of neuro-visceral

() The Author(s). 2020 Open Access This article is distributed under the terms of the Creative Commons Attribution 4.0 International License (https://creativecommons. org/licenses/by-nc/4.0/), which permits unrestricted use, distribution, and non-commercial reproduction in any medium, provided you give appropriate credit to the original author(s) and the source, provide a link to the Creative Commons license, and indicate if changes were made. The Creative Commons Public Domain Dedication waiver (http://creativecommons.org/publicdomain/zero/1.0/) applies to the data made available in this article, unless otherwise stated. 

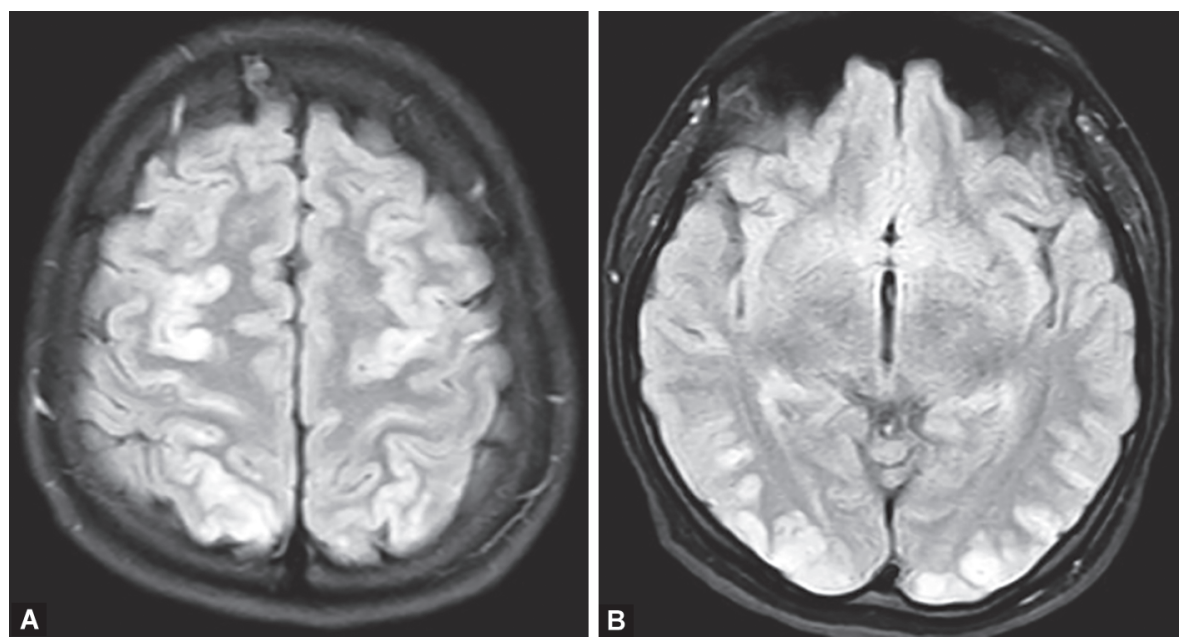

Figs 1A and B: T2-FLAIR axial MRI images demonstrating areas of hyperintensities in bilateral fronto-parietal and temporo-occipital lobes characteristic of PRES

symptoms that were managed with benzodiazepines. Her 24 hours urine porphobilinogen(PBG) levels ( $44.5 \mathrm{mg} / 24$ hours) (normal: $<2.5$ $\mathrm{mg} / 24$ hours) and 24 hours urinary amino levulinic acid levels $(77.7$ $\mathrm{mg} /$ day) (normal: $0.25-6.5 \mathrm{mg} / 24$ hours) were significantly elevated. She was initiated on Tab. Gabapentin in view of features suggestive of neuropathic pain in bilateral lower limbs. She was managed with antiepileptics (leviteracetam), antihypertensive medications (metoprolol, amlodipine, and clonidine), and benzodiazepines (clonazepam).

On day 8 , in view of persistent abdominal pain and neurovisceral symptoms, she was initiated on Inj Hematin ( $4 \mathrm{mg} / \mathrm{kg}$ ). She received a total of four doses of Inj. Hematin. Nerve conduction studies were negative for peripheral neuropathy. Serum/plasma, urine, and fecal porphyrin levels could not be evaluated due to nonavailability of the investigations in the institution and allied labs. Genetic testing of the patient and her siblings and family members was advised for confirmation of gene mutation.

She had shown clinical improvement in terms of colicky abdominal pain, neuropsychiatric symptoms, symptoms suggestive of peripheral neuropathy, and hypertension by day 10 . Her antihypertensive medications were optimized. The patient was advised optimization of antiepileptic medications with tapering doses of Leviteracetam and continuation of Briveracetam in view of increased incidence of psychosis associated with Leviteracetam. She was discharged on day 14 with advice to undergo genetic testing. Genetic testing revealed mutation in the gene coding for hydroxymethylbilane synthase (HMBS), which leads to development of AIP (Fig. 2).

\section{Discussion}

IP is one of a group of seven inherited disorders of heme synthesis. Symptoms include severe abdominal pain, constipation, autonomic nervous system disturbance, and electrolyte disturbances. Attacks of porphyria can be precipitated by medication, menstruation, and illness. It is caused by a deficiency of PBG deaminase, which leads to a build-up of PBG in the cytoplasm. Diagnosis is made by measuring 24 hours urine levels of PBG and urinary porphyrins during an acute attack which are markedly elevated. Our patient had markedly elevated 24 hours Urinary PBG levels.
Treatment of porphyria consists of a high carbohydrate diet supplemented with the use of intravenous glucose and hemelike substance infusions during acute attacks. These heme-like substances suppress 5 -aminolevulinic acid synthase and the accumulation of heme precursors. Management of seizures with inappropriate antiepileptics can actually worsen the condition. Many commonly used antiepileptics such as phenytoin and barbiturates will worsen symptoms. Levetiracetam is the preferred drug of choice should seizure medication be required. Patients are advised to avoid drugs that precipitate attacks. In the long-term, porphyria may lead to persistent neuromuscular weakness, high blood pressure, and liver cirrhosis.

PRES has been reported in only a handful of patients with AIP. $^{2-5}$ In this case report, we have presented a patient diagnosed with AIP with demonstrable PRES seen on MRI. PRES was first described in 1996, by Hinchey et al., as a clinical and radiological entity characterized by reversible headache, seizures, and visual loss accompanying edema seen especially in the occipital and parietal lobes. ${ }^{6}$ Treatment of PRES depends on the underlying cause. $^{7}$ PRES is often associated with hypertension causing a vasogenic edema. Our patient presented with high initial $B P$ recordings which was managed with IV Labetalol. This is noteworthy because the mechanism of PRES in AIP is unclear and has been suggested to be due to hypertension owing to autonomic dysfunction. An alternative suggestion is that depletion of nitric oxide synthase leads to vasoconstriction and edema. Nitric oxide synthase is a hemoprotein, and levels are reduced in AIP.

Abdominal pain has a wide range of possible causes; the physician must be aware of those rare but important causes of abdominal pain that may be missed. Porphyria is an important differential diagnosis in the patient with unexplained abdominal pain. Cortical manifestations of AIP remain rare, but this case report adds to a handful of cases worldwide associating AIP with PRES. AIP rarely presents with seizures, and few cases of epilepsia partialis continua have been described. ${ }^{8}$ This diagnosis requires vigilance, as treatment of seizures with antiepileptics may risk making the patient worse by precipitating the underlying disease. 


\begin{tabular}{|l|l|l|}
\hline Patient Information & Gender: NA & Age: 20 years \\
\hline Name: & \multicolumn{2}{|l|}{} \\
\hline Sample Information: & Sample Type: EDTA Whole Blood & Hospital/Clinic: \\
\hline Sample ID: G2M-10678 & Receiving Date: & Report Date: \\
\hline Collection Date: NA & $\begin{array}{l}\text { Test Name: Clinical Exome } \\
\text { Sequencing }\end{array}$ & Referred by: \\
\hline Test ID: G2M-64 & \\
\hline Clinical Indication/Summary/History: & \\
\hline Proband presented with Porphyria. &
\end{tabular}

\section{FAMILY HISTORY/ PEDIGREE:}

Not Mentioned

\section{RESULTS:}

\section{POSITIVE RESULTS}

(A LIKELY PATHOGENIC VARIANT WAS DETECTED RELATED TO THE CUINICAL PHENOTYPE)

\begin{tabular}{|c|c|c|c|c|c|c|}
\hline GENE & LOCATION & VARIANT & ZYGOSITY & DISEASE & INHERIAANCE & INTERPRETATION \\
\hline $\begin{array}{c}\text { HMBS } \\
\text { (NM_000190) }\end{array}$ & Exon 9 & $\begin{array}{c}\text { C.S18G>A } \\
\text { P.(Arg173Gin) }\end{array}$ & Heterotygous & $\begin{array}{l}\text { Porphyria, acute } \\
\text { intermittent }(176000)\end{array}$ & $\begin{array}{l}\text { Autosomal } \\
\text { dominant }\end{array}$ & $\begin{array}{c}\text { UKELY } \\
\text { PATHOGENIC }\end{array}$ \\
\hline
\end{tabular}

Fig. 2: Genetic analysis report of the patient showing pathogenic variant of HMBS gene leading to AIP

\section{Conclusion}

Abdominal pain with neurological symptoms should prompt consideration of porphyria. Autonomic dysfunction in AIP can cause hypertension and hypertensive encephalopathy leading to development of PRES and seizures. Recognition of this association is important to prevent precipitating further attacks of porphyria due to inappropriate antiepileptics.

\section{References}

1. Bonkovsky HL, Maddukuri VC, Yazici C, Anderson KE, Bissell DM, Bloomer JR, et al. Acute porphyrias in the USA: features of 108 subjects from porphyria consortium. Am J Med 2014;127(12):12331241. DOI: 10.1016/j.amjmed.2014.06.036.

2. Celik M, Forta H, Dalkiliç T, Babacan G. MRI reveals reversible lesions resembling posterior reversible encephalopathy in porphyria. Neuroradiology 2002;44(10):839-841. DOI: 10.1007/s00234-0020823-x.
3. King $P$, Bragdon A. MRI reveals multiple reversible cerebral lesions in an attack of acute intermittent porphyria. Neurology 1991;41(8):13001302. DOI: 10.1212/WNL.41.8.1300.

4. Garg RK. Acute intermittent porphyria: a cause of posterior leukoencephalopathy syndrome. J Assoc Physicians India 2000;48(6):658.

5. Shen FC, Hsieh $\mathrm{CH}$, Huang $\mathrm{CR}$, Lui CC, Tai WC, Chuang YC. Acute intermittent porphyria presenting as acute pancreatitis and posterior reversible encephalopathy syndrome. Acta Neurol Taiwan 2008;17(3):177-183.

6. Pedraza R, Marik P, Varon P. Posterior reversible encephalopathy syndrome: a review. Crit Care Shock 2009;12:135-143.

7. Hinchey J, Chaves C, Appignani B, Breen J, Pao L, Wang A, et al. A reversible posterior leukoencephalopathy syndrome. $\mathrm{N}$ Engl J Med 1996;334(8):494-500. DOI: 10.1056/NEJM1996022233 40803.

8. Tran TPY, Leduc K, Savard M, Dupré N, Rivest D, Nguyen DK. Acute porphyria presenting as epilepsia partialis continua. Case Rep Neurol 2013;5(2):116-124. DOI: 10.1159/000353279. 